\title{
CHANDLER ON CHANGE
}

\author{
GEORGE ENGLEBRETSEN \\ Bishop's University \\ Lenorvillo, Quebec
}

One of the oldest questions in metaphysics is the one concerning how an object can survive change. Can an object undergo alteration and still be the (numerically) same individual? One of the classic answers to this question is almost as old as the question itself. In spite of one or two important rivals over the centuries, it remains, I believe, a powerful and effective response to the question of change. Unfortunately, while this solution is not universally accepted now by philosophers (what is?!), it is, after all this time, still too often badly misunderstood.

The solution I have in mind is Aristotele's. Recently it has been expounded and used (correctly, I think) by Michael Loux in his Substance and Attribute: a Study in Ontology. However, in his critical notice of Loux's book Hugh S. Chandler ${ }^{2}$ has again demonstrated that Aristotle's solution can still be misunderstood.

So how can an object change and yet remain the same thing it was before the change? Indeed, does it? Over a span of a lifetime the vast majority of cells in my body have died (thus far not all at once) and been (usually) replaced by new ones. Thus most of the cells which constituted me at birth no longer constitute me. Over the years new ones have taken their places. Yet surely, on any account, I am the same person my mother gave birth to on my birthday. I have changed -yet remained the same. Consider a second case. The Tower of Pisa was once perpendicular. Now it leans. It

1 Dordrecht, 1978.

2 Philosophical Review (April, 1980), pp. 317-320. 
has undergone a change- yet remains the same tower. And, finally, a third case. The artist decides to construct a collage. He has just finished reading his copy of Santayana's The Sense of Beauty. He tears the book apart, literally. Eventually all the pages, the covers, the biding material, and so forth are reassembled in a flat, haphazard array on a large canvas. The book has undergone a change - has it remained the same book?

As we all know, there were some philosophers before Aristotle who claimed that change was impossible, that nothing ever changes. There were others who claimed that everything changes - all the time. His teacher had tried to admit both change and immutability by positing, in effect, two realms. In one realm, the world of Becoming, things change all the time. In the other world, the world of Being, the world of Forms, nothing ever changes. Forms are immutable. Aristotle set himself the task of accounting for a single, unified world (our everyday world of experience) in which some things are immutable and others sometimes change. As he saw, common sense at least suggests that ours is a world of both change and permanence.

Now, as it turns out, Aristotle's theory of change depends upon his theory of the nature of objects. Objects have properties. When an object changes we tend to account for it by saying that it changed some of its properties. However, some philosophers have held that an object cannot be anything other than its properties. Thus, the red ball in my left hand is nothing more than a collection of properties: redness, sphericality, hardness, coolness, etc. On this account (Berkeley is a good example of a philosopher who held this sort of view), when an object changes the properties which constitute it change. But since the object just is the set of all those properties, the object cannot survive the change. In change the object is replaced by a new one. The collection of properties is replaced by a new (perhaps only slightly different) collection of properties. On this theory objects can change - but they cannot survive that change. We might call 
the sort of change which an object cannot survive annihilation. Given the theory just outlined, every case of annihilation seems to be accompanied by the creation of a new object (collection of properties).

Not all philosophers, of course, accept such a theory of objects and how they change. Many would argue that an object is not just a collection of properties. An object is something else plus a collection of properties (Locke held this sort of view). This something else, call it a substratum, is what, according to this second theory, guarantees than an object can survive change. It survives change, is not annihilated, because throughout the change the substratum remains. And a substratum itself cannot in any way change since it has no properties. It is bare. The ball in my left hand is red or blue, warm or cool, but the bare substratum which (along with the properties the ball actually has) constitutes it has neither color nor temperature. Indeed, on this view, the property of being a ball is one of the properties along with redness and coolness. Any property, including the property of being a ball, could be removed or replaced and yet, since the bare substratum always survives, the objet survives. On the first theory change seems always to be annihilation (and creation). On the second theory no change is viewed as annihilation or creation.

We live in a world of things which, as Aristotle saw, come to be and pass away. Ours is a world in which some things are created and some things are annihilated. I came to be (was created) at my conception, or birth, or sometime between these. I will pass away (be annihilated), at my death. The artist's copy of The Sense of Beauty was annihilated by him. Our world is also, as Aristotle again saw, one in which some things change and yet are not annihilated by that change. A world in which some things survive change. I have survived my change from infant to adult. The Tower of Pisa has (so far) survived its change in attitude.

A theory which seeks to admit and account for such things as these must offer a concept of objects quite different from 
either the one offered by Berkeley or the one offered by Locke. For Aristotle, a substance is formed matter (or, equivalently, enmattered form). Matter and form are the two principles which account for any object. Contra Locke, a substance is not a bare substratum plus properties. Contra Berkeley, a substance is more than just its properties. What makes Aristotle's substance more than just Berkeley's properties is not Locke's bare substratum, however. For Aristotle a bare substratum would just be bare matter. On his account no matter is just bare matter. It is always formed matter. Now the form of any thing is what it is - its essential nature. For example, Socrates is a man, this is a ball, the moon is a heavenly body. Notice that not every property of an object is what-it-is. This ball is red. But being red is how-it-is, not what-it-is. It is also in my left hand. But, again, being in my left hand is where-it-is, not what-it-is. Those properties are only accidental properties. The form of any thing, its whatit-is, its whatness, its nature, its essence, is essential to it. It is a necessary property of an object. An object, then, for Aristotle is a substance with accidental properties. The formal principle of that substance is its essence.

Three kinds of cases of change must be treated by an Aristotelian theory of substance: those in which an accidental property is removed or replaced; and those in which the matter is removed or replaced. The first kind of case is called accidental change. The Tower of Pisa underwent accidental change when it leaned. The thing which was straight and now leans is the substance, the tower. It survived the accidental change. The second kind of change is called substantial change. The artist's book underwent substantial change. In these cases the change is not just accidental. It is essential. Here the form has been replaced. A thing of the form book is replaced by a thing of the form collage. Compare the two cases now. With the tower both before and after the change we can ask 'How-is-it?' The answer before change is 'Straight'. The answer after change is 'Leaning'. But if we ask 'What is-it?', the answer is the same both before and after the change 
(viz. 'A tower'). However, in the case of the artist the question 'How is-it?' might very well get the same answer both before and after the change (e.g. 'Brittle', 'Old', or 'Yellow'). But the question 'What is-it?' must be answered by 'A book' before the change, and by 'A collage' after the change. A substantial change is a change in the sort of thing an object is, its essential nature - an accidental change is not.

What of the third kind of change? Notice here that in such cases, while we might say that the substance has changed because the matter has changed (and substance involves equally matter and form), the material principle of any thing is not what-it-is. Thus, such material change (such as all of us undergo as our cells are replaced) is not substantial change. I survive such change because I am the same substance both before and after the change. The form, the what-it-is, has not been removed or replaced.

We need account for only two kinds of change: change which can be survived (accidental change) and change which cannot be survived (substantial change). Loux calls this Aristotelian theory the "substance-theory". Here is what Chandler has said.

According to Loux, it follows from the substancetheory that each individual human being is necessarily a human, each geranium necessarily a geranium, and, presumably, each table necessarily a table... I would prefer to think that there is a possible world (called "Ovid") in which a beautiful young woman once turned into a laurel bush; and even in our more prosaic world, a table can be made into a door. ${ }^{3}$

Had Chandler properly understood what is involved in the substance-theory he would have recognized that nothing in that theory prohibits persons from changing into plants, nor tables being made into doors. The theory merely claims that in such cases where necessary properties (forms, essences,

3 Op. cit., pp. $319-320$. 
natures) are lost the change is not just accidental - it is substantial. Note that even Chandler has chosen a set of locutions which enforce this distinction between two kinds of change. A young woman can turn mean. But she turns into a laurel bush. A table can be made narrower. But it is made into a door. As long as Daphne was she was necessarily a human. She did not survive the (substantial) change into a laurel bush. The laurel bush she changed into was not Daphne, who had ceased to be. It was a laurel bush, necessarily. Being a laurel bush is what-it-is. Since no substance can have two different natures, no substance can change into a laurel bush and still remain a human. Consider: 'Where is your table?' 'Gone. I made it into a door.' And: 'Where is your copy of The Sense of Beatuy?' 'It is no more. I made a collage of it.'

What Chandler has failed to see is that on the Aristotelian substance-theory the essential nature of any object can be lost. But, in such cases, the object ceases to be. Chandler has mistakenly concluded that because, on such a theory, an object must satisfy its nature necessarily it must do so eternally. Yet, as we have seen, this is clearly not the case. On the Aristotelian theory, to say that an object satisfies its nature necessarily is only to say that it satisfies its nature as long as it exists. That is why any object can undergo substantial change (change what-it-is) - but no object can survive such change. 